\title{
Pharmacists In National Public Health Programs In India: A Pilot Study Highlighting Physicians' Perceptions
}

\author{
Siva Prasada Reddy Maddirala Venkata ${ }^{1,2}$, Peter Kielgast ${ }^{2}$, Ubaidulla Udhumansha ${ }^{3}$, Marja Airaksinen ${ }^{1}$ \\ ${ }^{1}$ Clinical Pharmacy Unit, Division of Pharmacology and Pharmacotherapy, University of Helsinki, Helsinki, FINLAND. \\ ${ }^{2}$ Taastrup Pharmacy, Taastrup, DENMARK. \\ ${ }^{3}$ Department of Pharmaceutics, C. L. Baid Metha College of Pharmacy, Chennai, INDIA
}

\begin{abstract}
Background: Community pharmacists could play more potential role when finding ways to allocate effectively limited healthcare resources in primary care in many developing countries, including India. Pharmacists could participate in national public health programs, and cooperate effectively with other members of health care team. This small-scale pilot study was designed to develop a method for characterizing physicians' perceptions on the role of pharmacists in public health and patient care in India. Methods: Six volunteers visited 800 physicians in Southern region in India and collected data in 2014. The survey tool consisted of 28 structured questions concerning: (i) physicians' experiences of cooperation with pharmacists; (ii) physicians' general opinion on pharmacists' involvement in National Public Health Programs (NPHPs) in India; and (iii) pharmacists' involvement in 11 major NPHPs. The data were collated and extracted and descriptive statistical analysis was conducted by SAS (version 9.3). Results: Of total 800 physicians contacted, 129 responded. Of the responding physicians $98 \%$ were comfortable with pharmacists' roles in general, $96 \%$ were comfortable or somewhat comfortable to collaborate with pharmacists, and $82 \%$ regarded pharmacists as part of health care team. The physicians with shorter professional practice were more positive on pharmacists' involvement in NPHPs than physicians having at least 11 years' experience. Overall response of accepting pharmacists' role and
\end{abstract}

involvement in NPHPs was positive, Pulse Polio, HIV/AIDS, Tuberculosis and Tobacco control, and Leprosy eradication programs being the top NPHPs where physicians perceived pharmacists had a role to play. Conclusion: This small-scale pilot study indicates that Indian physicians are willing to collaborate with pharmacists and are comfortable to involve them in the health care team. The survey also revealed differences in opinions between junior and senior physicians: the longer physicians' practice experience was, the less favorable they were for pharmacists' involvement in NPHPS.

Key words: National Public Health Programs, Pharmacists India, Healthcare, Cooperative practice, Physicians, Pharmacist role in public health.

Correspondence :

Siva Prasada Reddy Maddirala Venkata, MPharm, RPh,

Clinical Pharmacy Group, Division of Pharmacology and Pharmacotherapy,

University of Helsinki, Viikinkaari 9, Biocenter 2, 00014 Helsinki, Finland.

Taastrup Pharmacy, Taastrup Hovedgade 60 Taastrup, DK-2630, DENMARK.

Email: prassu117@gmail.com

DOI: 10.5530/jyp.2017.9.10

\section{INTRODUCTION}

Manpower for health services has been described as the heart of the health system in any country.', ${ }^{1,2}$ World health workforce is facing significant challenges. With an estimated shortage of more than four million health workers worldwide, the global health workforce crisis is possibly the greatest health system constraint on countries seeking to meet their 2015 Millennium Development goals (MDGs). ${ }^{3}$ As identified by the World Health report 2006, India is 1 of 57 countries facing Human Resources for Health crisis. ${ }^{4,5}$ In India, the latest advances in medicine are available to people who can pay, but the vast underclass, 800 million people or more, have little or no access to healthcare. ${ }^{6}$ The public health system in India has a shortage of medical and paramedical personnel. Total number of doctors registered in the country was 885,233 (March 2013). ${ }^{7}$ Government estimates, based on vacancies in sanctioned posts, indicate that $18 \%$ of primary health centers are without a doctor, about $38 \%$ are without a laboratory technician, and $16 \%$ are without a pharmacist. ${ }^{8}$

Community pharmacists could play more potential role when finding ways to allocate effectively limited healthcare resources in primary care in many developing countries, including India. The role of pharmacists in the health care system has been highlighted by World Health Organization (WHO). Already in 1994, WHO resolution WHA 47.12 recognized the key role of pharmacists in public health, particularly in the field of medicines. ${ }^{9}$ Even earlier, in 1988, World Health Organization
(WHO) Consultative Group, New Delhi, emphasized pharmacists' involvement in health promotion campaigns and disease prevention both in local communities and at national level. The report also emphasized that pharmacists should "actively participate in national health programs", and "communicate and cooperate effectively with the other members of the health care team". ${ }^{10}$

There are over a million registered pharmacists in India working in various facets of pharmacy. Though there is such large presence, pharmacists both in public and private sector still remain largely an untapped resource in India. ${ }^{11-13}$ One of the glaring examples of this is reflected by the fact that the pharmacists does not find even a mention in National Health Policy $2002^{14}$ and National Pharmaceutical Policy. ${ }^{15}$ The same applies to 9 out 11 National Public Health Programs (NPHPs) run by the government of India, namely leprosy and vector borne disease control, mental health, deafness and blindness control, pulse polio, universal immunization, health care of elderly and tobacco control programs. ${ }^{16}$ Pharmacists' involvement in HIV/AIDS prevention and control; and tuberculosis control programs has recently rolled out. ${ }^{14}$

Physicians are opinion leaders in health care policy making, and thus, in key position for building up strategies for pharmacists' involvement in national public health programs. This small-scale pilot study was designed to develop a method for characterizing physicians' perceptions on the role of pharmacists in public health and patient care. This evidence

This is an open access article distributed under the terms of the Creative Commons Attribution-NonCommercial-ShareAlike 4.0 License, which allows others to remix, tweak, and build upon the work non-commercially, as long as the author is credited and the new creations are licensed under the identical terms. 
Table 1: Characteristics of the responding physicians (\% of the respondents, $n=129$ )

\begin{tabular}{|c|c|}
\hline Variable & n (\%) \\
\hline \multicolumn{2}{|l|}{ Gender } \\
\hline Male & $107(83)$ \\
\hline Female & $22(17)$ \\
\hline \multicolumn{2}{|l|}{ Age, years } \\
\hline$\leq 30$ & $36(28)$ \\
\hline $31-40$ & $47(36)$ \\
\hline $41-50$ & $20(16)$ \\
\hline$>50$ & $26(20)$ \\
\hline \multicolumn{2}{|l|}{ Education qualification } \\
\hline MBBS & $53(41)$ \\
\hline $\mathrm{MS} / \mathrm{MD}$ & $69(53)$ \\
\hline Other & $7(05)$ \\
\hline \multicolumn{2}{|l|}{ Number of year in practice } \\
\hline$<5$ & $55(43)$ \\
\hline $5-10$ & $33(26)$ \\
\hline $11-15$ & $15(12)$ \\
\hline$>15$ & $26(20)$ \\
\hline \multicolumn{2}{|l|}{ Current designation } \\
\hline Family doctor & $45(35)$ \\
\hline Medical officer & $8(06)$ \\
\hline $\mathrm{CMO}$ & $3(02)$ \\
\hline Surgeon & $18(14)$ \\
\hline Other & $55(43)$ \\
\hline \multicolumn{2}{|l|}{ Current practice setting } \\
\hline Private & $16(12)$ \\
\hline Corporate & $56(43)$ \\
\hline Government & $2(02)$ \\
\hline Other & $55(43)$ \\
\hline
\end{tabular}

could guide pharmacists in preparing to take active part in NPHPs and to appear on national health and pharmaceutical policies. Pharmacists' involvement in national public health programs (NPHPs) in this study means active participation in one or more of 11 NPHPs run by the government of India. ${ }^{17}$

\section{METHOD}

Study design: A cross-sectional survey to a convenience sample of physicians in Southern region in India.

\section{Study instrument}

The method of this cross-sectional small-scale pilot study was designed using the following three studies as baseline references: "Physician perceptions of pharmacist roles in a primary care setting in Qatar,"18 "Professional training and roles of community pharmacists in Malaysia: views from general medical practitioners" ${ }^{19}$ and "Extending the roles of community pharmacists: views from general medical practitioners" ${ }^{20}$

A survey tool was developed with 28 structured questions divided into three sections: (i) physicians' experiences of interaction and cooperation with pharmacists; (ii) physicians' general opinion on pharmacists' involvement in NPHPs; (iii) Physicians' opinion on pharmacists' role in 11 major individual NPHPs. The questionnaire was initially validated by two professors, two pharmacists and two physicians for content before data collection. Their views and comments were considered and incorporated, where appropriate, into the final questionnaire.
Six volunteers personally visited 800 physicians working in private hospitals and as independent practitioners in Southern region in India and collected data between March - November 2014. Well in advance, the volunteers were briefed about the importance of the study and process on how to collect the data. The volunteers made two visits: the first visit was to explain and deliver the print version of the survey tool, then the second visit to remind and collect the data. To document the consent of physicians and to maintain authenticity of the study, participating physicians were requested to fill the questionnaire personally and sign and stamp it at the end of the survey form.

To maintain anonymity of the respondents, data forms were numbered and the numbers were used as IDs during the data entry in University of Helsinki's E-lomake online survey portal. The data were collated and extracted and descriptive statistical analysis was conducted by SAS (version 9.3). Results are presents as frequencies and percentages. The physicians' perceptions of pharmacists' role in NPHPs were reflected according to length of their medical practice. Chi-square tests were used to determine if there were any statistical differences in the responses in this respect. For this purpose, the survey respondents were segregated into the following 4 groups based on the number of years of professional practice: Group A with less than 5 years of professional practice $(43 \%$, $\mathrm{n}=55)$; Group B with 5-10 years of practice ( $26 \%, \mathrm{n}=33)$, Group C with $11-15$ years of practice $(12 \%, n=15)$ and Group D with more than 15 years of practice $(20 \%, n=26)$.

\section{RESULTS}

Of total 800 physicians, 129 responded, leading to a response rate of $16 \%$ (Table 1). Of the respondents, $83 \%$ were men and $17 \%$ women with a median age of 34 years. Forty-one percent of the respondents had Bachelor of Medicine and Bachelor of Surgery (MBBS) degree and 53\% Post Graduate in Medicine (MD) and Master of Surgery (MS) as their highest academic degree. The respondents were working in various sectors, the highest proportion ( $43 \%$ of the respondents) being working in corporate hospitals at the time of the survey. Almost half (43\%) of the respondents had less than 5 years' experience in professional practice, $26 \%$ with 5-10 years, $15 \%$ with $11-15$ years and $20 \%$ with over 15 years of experience. Table 2 shows the results of the survey questions related to physicians' and pharmacists' interaction and collaboration in general. A majority (90\%) of the physicians had a pharmacy close to their practice and $88 \%$ of them reported referring patients to buy medicine from those close by pharmacies. Of all responding physicians, $81 \%$ indicated contacting their pharmacy frequently for professional matters, $68 \%$ of them on daily or at least weekly basis. Physicians with less than 5 years and 5-10 years of practice experience reported contacting pharmacists more frequently (96\% and $88 \%$, respectively) than physicians with $11-15$ years and over 15 years of professional experience (60\% and 54\%, respectively). A majority of the physicians also perceived that pharmacists were knowledgeable $(84 \%)$, service oriented $(83 \%)$ and were providing very sufficient or sufficient patient counseling on medicines to supplement physician's counselling, e.g., on administration, dosage and side effects. Again, this perception was more common in younger physicians with $<5$ years of practice experience (89\%) and 5-10 years of experience (75\%), than in senior physicians with 11-15 years' experience (53\%) and $>15$ years' experience (69\%). Almost all physicians (98\%) were comfortable with pharmacists' roles in general, $96 \%$ were comfortable or somewhat comfortable to collaborate with pharmacists and $82 \%$ regarded pharmacists as part of health care team.

Table 3 shows the results of physicians' general opinion on pharmacists' involvement in NPHPs. Around 50\% of all physicians regarded pharmacists as a mere vendor/dispenser of prescription drugs. The physicians with shorter professional practice (Group A and Group B) were more 
Table 2: Physicians' experiences of cooperation and interaction with pharmacists according to their years of professional practice ( $\%$ of the respondents. $n=129$ )

\begin{tabular}{|c|c|c|c|c|c|c|}
\hline \multirow[b]{2}{*}{ Question } & \multicolumn{6}{|c|}{ Responses according to years of professional practice, $n(\%)$} \\
\hline & $\begin{array}{c}\text { Total } \\
(n=129)\end{array}$ & $\begin{array}{l}<5 \text { yrs } \\
(n=55)\end{array}$ & $\begin{array}{c}5-10 \text { yrs } \\
(n=33)\end{array}$ & $\begin{array}{c}11-15 \text { yrs } \\
(n=15)\end{array}$ & $\begin{array}{l}>15 \text { yrs } \\
(n=26)\end{array}$ & p-value* \\
\hline \multicolumn{7}{|c|}{ Is there a pharmacy attached or close to your practice? } \\
\hline Yes & $116(90)$ & $55(100)$ & $32(97)$ & $12(80)$ & $17(65)$ & \multirow{2}{*}{$<0.001$} \\
\hline No & $13(10)$ & $0(0)$ & $01(03)$ & $03(20)$ & $9(35)$ & \\
\hline \multicolumn{7}{|c|}{ Do you refer your patients with prescription to a pharmacy in your practice area to buy their medicine? } \\
\hline Yes & $114(88)$ & $51(93)$ & $31(94)$ & $14(93)$ & $18(69)$ & \multirow{2}{*}{$<0.001$} \\
\hline No & $15(12)$ & $4(07)$ & $2(06)$ & $1(07)$ & $8(31)$ & \\
\hline \multicolumn{7}{|c|}{ Do you contact your pharmacy frequently for professional matters? } \\
\hline Yes & $105(81)$ & $53(96)$ & $29(88)$ & $9(60)$ & $14(54)$ & \multirow{2}{*}{$<0.001$} \\
\hline No & $24(19)$ & $2(04)$ & $4(12)$ & $6(40)$ & $12(46)$ & \\
\hline \multicolumn{7}{|c|}{ On an average, please estimate the frequency of your interactions with a pharmacist } \\
\hline Every day & $40(31)$ & $17(31)$ & $15(45)$ & $4(27)$ & $4(15)$ & \multirow{4}{*}{$<0.001$} \\
\hline Once or more than once a week & $48(37)$ & $20(36)$ & $13(39)$ & $5(33)$ & $10(38)$ & \\
\hline Once or more than once a month & $22(17)$ & $15(27)$ & $4(12)$ & $1(07)$ & $2(08)$ & \\
\hline Less than once a month & $19(15)$ & $3(5)$ & $1(03)$ & $5(33)$ & $10(38)$ & \\
\hline \multicolumn{7}{|c|}{ Do you think that your pharmacist is knowledgeable? } \\
\hline Yes & $109(84)$ & $54(98)$ & $27(82)$ & $6(40)$ & $22(85)$ & \multirow{2}{*}{$<0.001$} \\
\hline No & $20(16)$ & $1(02)$ & $6(18)$ & $9(60)$ & $4(15)$ & \\
\hline \multicolumn{7}{|c|}{ Do you think that your pharmacist is service oriented? } \\
\hline Yes & $107(83)$ & $53(96)$ & $26(79)$ & $12(80)$ & $16(62)$ & \multirow{2}{*}{0.001} \\
\hline No & $22(17)$ & $2(04)$ & $7(21)$ & $3(20)$ & $10(38)$ & \\
\hline
\end{tabular}

Do you think the pharmacy / your pharmacist is providing patient counseling on medicine, administration, dosage, side effects etc., to supplement your counseling, is at a satisfactory level?

\begin{tabular}{|c|c|c|c|c|c|c|}
\hline Very much sufficient & $31(24)$ & $10(18)$ & $14(42)$ & $2(13)$ & $5(19)$ & \multirow{5}{*}{0.013} \\
\hline Sufficient & $69(53)$ & $39(71)$ & $11(33)$ & $6(40)$ & $13(50)$ & \\
\hline Neutral & $15(12)$ & $3(05)$ & $4(12)$ & $4(27)$ & $4(15)$ & \\
\hline Not sufficient & $10(08)$ & $3(05)$ & $3(09)$ & $1(07)$ & $3(12)$ & \\
\hline Totally nsufficient & $4(03)$ & $0(0)$ & $1(03)$ & $2(13)$ & $1(04)$ & \\
\hline \multicolumn{7}{|c|}{ Please rate your comfort with pharmacist roles described } \\
\hline Very comfortable & $81(63)$ & $40(73)$ & $24(73)$ & $03(20)$ & $14(54)$ & \multirow{3}{*}{0.006} \\
\hline Somewhat comfortable & $45(35)$ & $14(25)$ & $08(24)$ & $11(73)$ & $12(46)$ & \\
\hline Uncomfortable & $03(02)$ & $01(02)$ & $01(03)$ & $01(07)$ & $0(0)$ & \\
\hline \multicolumn{7}{|c|}{ Do you have any barriers to collaborate with pharmacists as a part of health care team? } \\
\hline Very comfortable & $77(60)$ & $36(65)$ & $27(82)$ & $05(33)$ & $09(35)$ & \multirow{3}{*}{0.003} \\
\hline Somewhat comfortable & $47(36)$ & $18(33)$ & $05(15)$ & $09(60)$ & $15(58)$ & \\
\hline Uncomfortable & $05(04)$ & $01(02)$ & $01(03)$ & $01(07)$ & $02(08)$ & \\
\hline \multicolumn{7}{|c|}{ Do you see pharmacists as a part of health care team? } \\
\hline Yes & $106(82)$ & $53(96)$ & $29(88)$ & $10(67)$ & $14(54)$ & \multirow{3}{*}{$<0.001$} \\
\hline No & $10(08)$ & $02(04)$ & $01(03)$ & $01(07)$ & $06(23)$ & \\
\hline No opinion & $13(10)$ & $0(0)$ & $03(09)$ & $04(27)$ & $06(23)$ & \\
\hline
\end{tabular}

Chi-square test was used.

${ }^{*}<0.05$ is considered significant. 
Table 3. Physicians general opinions on pharmacists' involvement in National Public Health Programs (NPHPs) according to their years of professional practice (\% of the respondents, $n=129)$

\begin{tabular}{|c|c|c|c|c|c|c|}
\hline \multirow[b]{2}{*}{ Question } & \multicolumn{6}{|c|}{ Response according to years of professional practice, $n(\%)$} \\
\hline & $\begin{array}{c}\text { Total } \\
(n=129)\end{array}$ & $\begin{array}{l}<5 y r s \\
(n=55)\end{array}$ & $\begin{array}{c}5-10 y r s \\
(n=33)\end{array}$ & $\begin{array}{c}11-15 \text { yrs } \\
(n=15)\end{array}$ & $\begin{array}{l}>15 \text { yrs } \\
(n=26)\end{array}$ & p-value* \\
\hline \multicolumn{7}{|c|}{ Do you see the pharmacist as a mere vendor/dispenser of prescription drugs? } \\
\hline Yes & $57(44)$ & $14(25)$ & $23(70)$ & $7(47)$ & $13(50)$ & \multirow{3}{*}{$<0.006$} \\
\hline No & $64(50)$ & $39(71)$ & $7(21)$ & $8(53)$ & $10(38)$ & \\
\hline Do not know & $08(06)$ & $02(04)$ & $3(09)$ & $0(0)$ & $3(12)$ & \\
\hline \multicolumn{7}{|c|}{ Your perception on pharmacists' role in National Public Health Programs: } \\
\hline Positive & $84(65)$ & $46(84)$ & $25(76)$ & $6(40)$ & $7(27)$ & \multirow{4}{*}{$<0.001$} \\
\hline Neutral & $24(19)$ & $04(07)$ & $5(15)$ & $7(47)$ & $8(31)$ & \\
\hline Negative & $06(05)$ & $01(02)$ & $0(0)$ & $0(0) 2(13)$ & $5(19)$ & \\
\hline No opinion & $15(12)$ & $04(07)$ & $3(09)$ & & $6(23)$ & \\
\hline \multicolumn{7}{|c|}{ Do you feel pharmacists have an important role to play in public health programs? } \\
\hline Yes, very important & $85(66)$ & $48(87)$ & $23(70)$ & $07(47)$ & $07(27)$ & \multirow{4}{*}{$<0.001$} \\
\hline Yes, moderately important & $22(17)$ & $04(07)$ & $06(18)$ & $03(20)$ & $09(35)$ & \\
\hline No, not important & $05(04)$ & $01(02)$ & $0(0)$ & $01(07)$ & $03(12)$ & \\
\hline No opinion & $15(12)$ & $02(04)$ & $04(12)$ & $04(27)$ & $07(27)$ & \\
\hline \multicolumn{7}{|c|}{ Do you think it is important to include pharmacists in National public health programs? } \\
\hline Yes, very important & $85(66)$ & $45(82)$ & $24(73)$ & $08(53)$ & $08(31)$ & \multirow{4}{*}{$<0.001$} \\
\hline Yes, moderately important & $22(17)$ & $06(11)$ & $05(15)$ & $03(20)$ & $08(31)$ & \\
\hline No, not important & $10(08)$ & $02(04)$ & $0(0)$ & $01(07)$ & $07(27)$ & \\
\hline No opinion & $12(09)$ & $02(04)$ & $04(12)$ & $03(20)$ & $03(12)$ & \\
\hline \multicolumn{7}{|c|}{ Do you feel that pharmacists' current knowledge on various public health programs is sufficient? } \\
\hline Very much sufficient & $29(22)$ & $11(20)$ & $14(42)$ & $02(13)$ & $02(08)$ & \multirow{5}{*}{$<0.001$} \\
\hline Sufficient & $48(37)$ & $33(60)$ & $06(18)$ & $02(13)$ & $07(27)$ & \\
\hline Neutral & $14(11)$ & $04(07)$ & $03(09)$ & $04(27)$ & $03(12)$ & \\
\hline Not sufficient & $25(19)$ & $06(11)$ & $07(21)$ & $04(27)$ & $08(31)$ & \\
\hline Totally insufficient & $13(10)$ & $01(02)$ & $03(09)$ & $03(20)$ & $06(23)$ & \\
\hline
\end{tabular}

Chi-square test was used.

$*<0.05$ is considered significant.

positive ( $84 \%$ and $76 \%$, respectively) on pharmacists' involvement in NPHPs than physicians having at least 11 years' experience (Group C: $40 \%$ and Group D: $27 \%$, respectively). In the same manner, more physicians from Group A and B ( $83 \%$ and $94 \%$, respectively), perceived that the pharmacists have very important to moderately important role in public health programs, compared to physicians from Group $\mathrm{C}$ and D (67\% and $62 \%$, respectively). However, $93 \%, 83 \%, 73 \%$ and $62 \%$ of physicians from Group A, B, C and D, respectively, perceived that it is important or moderately important to involve pharmacists in NPHPs. The respective proportions of physicians estimating pharmacists' knowledge sufficient for the involvement were $80 \%, 60 \%, 26 \%$ and $35 \%, p<0.001$. The results show a trend in acceptance of pharmacists' involvement in NPHPs based on the length of physicians' professional experience: the longer the physicians' practice experience was, the less favorable they were for pharmacists' involvement in NPHPs.

Table 4 shows the results of physicians' opinions on pharmacists' involvement in 11 selected NPHPs in India. Overall response of accepting pharmacists' role and involvement in NPHPs was very positive, ranging from $67-83 \%$ for different programs. Similar trend as in the previous section was found again, where more the physicians' practice experience, the less the acceptance for pharmacists' role in particular NPHPs. The trends in their opinions were quite similar in all selected NPHPs. As per the results, Pulse Polio, HIV/AIDS, Tuberculosis and Tobacco control and Leprosy eradication programs were the top five NPHPs where physicians perceived that the pharmacists has a role to play.

\section{DISCUSSION}

This small-scale pilot study indicates that Indian physicians are willing to collaborate with pharmacists and are comfortable to involve them in the health care team. The same trend was found in the physicians' general opinions of interaction and cooperation with pharmacists; their general opinion on pharmacists' involvement in NPHPs; and their opinion on pharmacists' role in 11 major individual NPHPs in India. The survey also revealed differences in opinions between junior and senior physicians: the longer the physicians' practice experience was, the less favorable they were for pharmacists' involvement in NPHPs.

Differences in opinions between junior and senior physicians concerning pharmacists' involvement in NPHPs can be related to pharmacists' qualifications in India. Most of the pharmacists practicing in community pharmacies in India are DPharm holders with 2 years education ${ }^{21}$ and without continuing education..$^{22}$ Physicians with more than 10 years practice experience may build their perceptions of pharmacists' skills and knowledge on these least trained professionals that use the same title as, e.g., PharmDs who have three times longer training which is 
Table 4: Physicians' opinions on pharmacists' involvement in the major national public health programs established by Indian Government (\% of the respondents according to their years of professional practice, $n=129$ )

\begin{tabular}{cccccc}
\hline Title of the National Public & \multicolumn{5}{c}{ Response according to years of professional practice, $n(\%)$} \\
$\begin{array}{c}\text { Health Program and its } \\
\text { objectives }\end{array}$ & Total & $<5$ yrs & $5-10$ yrs & $11-15$ yrs & $>15$ yrs \\
$(n=129)$ & $(n=55)$ & $(n=33)$ & $(n=15)$ & $(n=26)$ & $p$-value* \\
\hline
\end{tabular}

\section{HIV/AIDS Control Program}

Objectives: NACO envisions in India where every person living with HIV has access to quality care and is treated with dignity. Effective prevention, care and support for HIV/AIDS is possible in an environment where human rights are respected and where those infected or affected by HIV/AIDS live a life without stigma and discrimination.

Can the pharmacist play a role in HIV/AIDS Control Program?

\begin{tabular}{|c|c|c|c|c|c|c|}
\hline Yes & $107(83)$ & $54(98)$ & $28(85)$ & $12(80)$ & $13(50)$ & \\
\hline No & $17(13)$ & $01(02)$ & $03(09)$ & $01(07)$ & $12(46)$ & $<0.001$ \\
\hline Do not know & $05(04)$ & $0(0)$ & $02(06)$ & $02(13)$ & $01(04)$ & \\
\hline
\end{tabular}

Revised National Tuberculosis Control Program (RNTCP)

The objective of TB control Program is to achieve and maintain cure rate of at least $85 \%$ in new sputum positive pulmonary TB patients, and to achieve and maintain detection of at least $70 \%$ of such cases. Directly Observed Treatment is highlight of this program.

Can the pharmacist play a role in Revised National Tuberculosis Control Program (RNTCP)?

\begin{tabular}{|c|c|c|c|c|c|c|}
\hline Yes & $106(82)$ & $55(100)$ & $28(85)$ & $10(67)$ & $13(50)$ & \\
\hline No & $18(14)$ & $0(0)$ & 05 (15) & $01(06)$ & $12(46)$ & $<0.001$ \\
\hline Do not know & $05(04)$ & $0(0)$ & $0(0)$ & $04(27)$ & $01(04)$ & \\
\hline
\end{tabular}

National Vector Borne Disease Control Program (NVBDCP)

The objective of the program is to prevent and control Malaria, Dengue, Lymphatic Filariasis, Kala-azar, Japanese Encephalitis and Chikungunya in India.

Can the pharmacist play a role in National Vector Borne Disease Control program (NVBDCP)?

\begin{tabular}{|c|c|c|c|c|c|c|}
\hline Yes & $94(73)$ & $52(95)$ & $25(76)$ & $08(53)$ & $09(35)$ & \\
\hline No & $27(21)$ & $03(05)$ & $06(18)$ & $03(20)$ & $15(58)$ & $<0.001$ \\
\hline Do not know & $08(06)$ & $0(0)$ & $02(06)$ & $04(27)$ & $02(08)$ & \\
\hline
\end{tabular}

National Leprosy Eradication Program (NLEP)
Objectives of the program: Early detection \& complete treatment of new leprosy cases. Carrying out house hold contact survey in detection. Early diagnosis \& prompt MDT, through routine and special efforts. Information, Education \& Communication (IEC) activities in the community to improve self reporting to Primary Health Centre (PHC) and reduction of stigma. Intensive monitoring and supervision at Primary Health Centre/ Community Health Centre.

Can the pharmacist play a role in National Leprosy Eradication Program (NLEP)?

\begin{tabular}{|c|c|c|c|c|c|c|}
\hline Yes & $99(77)$ & $54(98)$ & $25(76)$ & $10(67)$ & $10(38)$ & \\
\hline No & $19(15)$ & $01(02)$ & 05 (15) & $01(07)$ & $12(46)$ & $<0.001$ \\
\hline Do not know & $11(09)$ & $0(0)$ & $03(09)$ & $04(27)$ & $04(15)$ & \\
\hline
\end{tabular}

National Mental Health Program (NMHP)

Objectives: 1) To ensure the availability and accessibility of minimum mental healthcare for all in the foreseeable future, particularly to the most vulnerable and underprivileged sections of the population; 2) To encourage the application of mental health knowledge in general healthcare and in social development; and 3) To promote community participation in the mental health service development and to stimulate efforts towards self-help in the community.

Can the pharmacist play a role in National Mental Health Program (NMHP)?

\begin{tabular}{|c|c|c|c|c|c|c|}
\hline Yes & $94(73)$ & $51(93)$ & $22(67)$ & $08(53)$ & $13(50)$ & \\
\hline No & $23(18)$ & $04(07)$ & $06(18)$ & $03(20)$ & $10(38)$ & $<0.001$ \\
\hline Do not know & $12(09)$ & $0(0)$ & 05 (15) & $04(27)$ & 03 (12) & \\
\hline
\end{tabular}

National Program for Prevention and Control of Deafness (NPPCD)

Objectives: 1) To prevent the avoidable hearing loss on account of disease or injury; 2) Early identification, diagnosis and treatment of ear problems responsible for hearing loss and deafness; and 3) To strengthen the existing intersectoral linkages for continuity of the rehabilitation program, for persons with deafness.

Can the pharmacist play a role in National Program for Prevention and Control of Deafness (NPPCD)?

\begin{tabular}{|c|c|c|c|c|c|c|}
\hline Yes & $88(68)$ & $49(89)$ & $25(76)$ & $06(40)$ & $08(31)$ & \\
\hline No & $35(27)$ & $06(11)$ & $7(21)$ & $05(33)$ & $17(65)$ & $<0.001$ \\
\hline not know & $06(05)$ & $0(0)$ & $1(03)$ & $04(27)$ & $01(04)$ & \\
\hline
\end{tabular}


Table 4: Con

\begin{tabular}{|c|c|c|c|c|c|c|}
\hline \multirow{2}{*}{$\begin{array}{c}\text { Title of the National Public } \\
\text { Health Program and its } \\
\text { objectives }\end{array}$} & \multicolumn{6}{|c|}{ Response according to years of professional practice, $n$ (\%) } \\
\hline & $\begin{array}{c}\text { Total } \\
(n=129)\end{array}$ & $\begin{array}{l}<5 \text { yrs } \\
(n=55)\end{array}$ & $\begin{array}{c}5-10 \text { yrs } \\
(n=33)\end{array}$ & $\begin{array}{c}11-15 \text { yrs } \\
(n=15)\end{array}$ & $\begin{array}{l}>15 \text { yrs } \\
(n=26)\end{array}$ & p-value* \\
\hline
\end{tabular}

National Program for Control of Blindness (NPCB)

Objectives: 1) To reduce the backlog of blindness through identification and treatment of blind at primary, secondary and tertiary levels; 2) Prevention of visual impairment; through provision of comprehensive eye care services and quality service delivery; 3 ) To enhance community awareness on eye care and lay stress on preventive measures; and 4) To secure participation of Voluntary organizations/Private Practitioners in eye care.

Can the pharmacist play a role in National Program for Control of Blindness (NPCB)?

\begin{tabular}{|c|c|c|c|c|c|c|}
\hline Yes & $87(67)$ & $50(91)$ & $24(73)$ & $07(47)$ & $06(23)$ & \\
\hline No & $30(23)$ & $05(9)$ & $06(18)$ & $05(33)$ & $14(54)$ & $<0.001$ \\
\hline Do not know & $12(09)$ & $0(0)$ & $03(09)$ & $03(20)$ & $06(23)$ & \\
\hline
\end{tabular}

Pulse Polio program

Objectives: Children in the age group of 0-5 years administered Polio drops during the national and sub-nationals immunization rounds. About 172 million children are immunized during each National Immunization Day.

Can the pharmacist play a role in Pulse Polio program?

\begin{tabular}{|c|c|c|c|c|c|c|}
\hline Yes & $108(84)$ & $53(96)$ & $30(91)$ & $11(73)$ & $14(54)$ & \\
\hline No & $17(13)$ & $02(04)$ & $01(03)$ & $03(20)$ & $11(42)$ & $<0.001$ \\
\hline Do not know & $04(03)$ & $0(0)$ & $02(06)$ & $01(07)$ & $01(04)$ & \\
\hline
\end{tabular}

Universal Immunization Program (UIP)

Objective: Protection of children from life threatening conditions by providing vaccination. Under UIP, following vaccines are provided: 1) BCG; 2) DPT; 3) OPV (oral polio vaccine); 4) Measles; 5) Hepatitis; 6) TT (Tetanus Toxoid) etc.

Can the pharmacist play a role in Universal Immunization Program (UIP)?

\begin{tabular}{|c|c|c|c|c|c|c|}
\hline Yes & $96(74)$ & $53(96)$ & $26(79)$ & $09(60)$ & $08(31)$ & \\
\hline No & $21(16)$ & $02(04)$ & $2(06)$ & $03(20)$ & $14(51)$ & $<0.001$ \\
\hline Do not know & $12(09)$ & $0(0)$ & $5(15)$ & $03(20)$ & $04(15)$ & \\
\hline
\end{tabular}

National Tobacco Control Program (NTCP)

Objectives: 1) To bring about greater awareness about the harmful effects of tobacco use and about the Tobacco control Laws; and 2) To facilitate effective implementation of the Tobacco Control Laws.

Can the pharmacist play a role in National Tobacco Control Program (NTCP)?

\begin{tabular}{|c|c|c|c|c|c|c|}
\hline Yes & 99 (77) & $52(95)$ & $28(85)$ & $09(60)$ & $10(38)$ & \\
\hline No & $22(17)$ & $03(05)$ & $03(09)$ & $03(20)$ & $13(50)$ & $<0.001$ \\
\hline Do not know & $08(06)$ & $0(0)$ & $02(06)$ & $03(20)$ & $03(12)$ & \\
\hline
\end{tabular}

National Program for Health Care of the Elderly (NPHCE)

Objective is to provide separate, specialized and comprehensive health care to the senior citizen at various level of State health care delivery system including outreach services.

Can the pharmacist play a role in National Program for Health Care of the Elderly (NPHCE)?

\begin{tabular}{cllllll} 
Yes & $93(72)$ & $53(96)$ & $25(76)$ & $08(53)$ & $07(27)$ & $16(62)$ \\
No & $25(19)$ & $01(02)$ & $04(12)$ & $04(27)$ & $03(12)$ \\
Do not know & $11(09)$ & $01(02)$ & $04(12)$ & $03(20)$ & $03(001$ \\
\hline
\end{tabular}

Chi-square test was used.

$*<0.05$ is considered significant.

also more clinically oriented. ${ }^{23}$ Thus, upcoming PharmD graduates with 6 years education (training initiated in 2008) focused mainly towards clinical and community aspects ${ }^{21}$ should be able to change collaborative practice models and physicians' perceptions in the future.

Most of the responding physicians had the opinion that pharmacists can take an important role in all the NPHPs. This provides pharmacists huge opportunities however, the pharmacists need proper training. This provides pharmacists huge opportunities to contribute to public health and patient care. However, practicing pharmacists need proper continuing education for being prepared for more patient-oriented practice. Some suitable continuing education is already available, e.g., the implementation of National Health Mission is already providing a course for BSc in Community Health for mid-level clinical care provider, including pharmacists. ${ }^{24}$ Such courses for in-service pharmacists would provide opportunities to create competences and collaborative networks needed when working as a part of community health services. Also the Planning Commission of India has approved schemes for "Setting up of college of pharmacy in Government medical colleges" to facilitate quality education and ensure availability of skilled competent workforce to the society. ${ }^{25}$ This initiative in long run, provide better collaborative opportunities for the pharmacists. 
To create such evidence, pharmacists need to make strategies with the help of professional associations. It is also important to conduct a separate study to understand reasons for these differences.

As per the results, Pulse Polio, HIV/AIDS, Tuberculosis-, Tobacco control and leprosy eradication programs were the top five NPHPs where physicians perceived that the pharmacists can play an important role. It is also important to note that, none of other programs selected were completely ignore or uninterested for the respondents (over $65 \%$ positive response). If the pharmacists are trained in NPHPs, this untapped potential of one million pharmacists can be utilized to supplement the health workforce in India to meet challenges in public health sector. Therefore, it is important to conduct a large scale study to understand the needs of training that is required for the pharmacists to make them part of NPHPs.

The World Health Organization (WHO) and its partners recognize interprofessional collaboration in education and practice as an innovative strategy. ${ }^{26}$ Strong working relationships between pharmacists and physicians are needed to optimize patient care. In a study from Canada reveals that community pharmacists and physicians agree that collaborative practice can optimize patient outcomes and would like to collaborate more. ${ }^{27}$ The Planning Commission of India has approved schemes for "Setting up of college of pharmacy in Government medical colleges" to facilitate quality education and ensure availability of skilled competent workforce to the society. ${ }^{24}$ This initiative in long run, provide better collaborative opportunities for the pharmacists.

Policy makers in India are yet to realize full potential of pharmacists' role in NPHPs. Physicians in this survey clearly indicated that pharmacists can play an important role in the major health programs and the physicians are willing to collaborate. A Malaysian study suggests that General Physicians (GPs) support the extension of community pharmacists' role in patient care activities, ${ }^{19}$ which is almost the same in this study. Another study conducted among pharmacy students revealed that 100\% of 282 students were willing to learn to extend their role in patient care and public health. ${ }^{28}$

Though the physicians are welcoming, it is also important that the pharmacists must be prepared and learn about the NPHPs, either through training programs or in the curriculum. Perceptions of physicians on pharmacists' role in RNTCP are welcoming. The RNTCP guidelines for the first time, have mentioned the word "pharmacist" as specialists with expertise in managing Multi-Drug-Resistant Tuberculosis (MDR-TB) ${ }^{29}$ which is another step forward. A good example to show pharmacist unpreparedness is, a study revealed that the pharmacists in retail outlets dispense anti-TB drugs, but they were not aware of existence of RNTCP, however, almost all of them were willing to learn and contribute to TB control. ${ }^{30}$ Hence, creating awareness on NPHPs and opportunities available for pharmacists should be actively promoted by national professional associations, so that pharmacists can take initiatives in NPHPs.

As both the pharmacists and physicians want pharmacists' involvement in NPHPs, now pharmacy professionals have to find ways to make pharmacists as part public health providers. A live example for such initiatives is, in South Africa, over the past few years, the government has introduced a range of initiatives to recruit and retain health professionals, including increase of pharmacists in public health sector commenced in 2001, mandatory one-year community service in public sector was introduced for all pharmacists following registration with the South African Pharmacy Council. Similar initiatives in collaboration with Pharmacy Council of India will improve pharmacists' image in society and with policy makers.

Role of professional associations in strengthening

\section{pharmacists position NPHPs}

Productive partnerships could be public-private-professional organizational collaborations. For example, All India Organisation of Chemists and Druggists (AIOCD) with its approximately 700,000 members and Indian Pharmaceutical Association has 10,000 members and also operates in 17 state branches and 33 local branches, which could be a potential resource to disseminate information on various NPHPs and utilize this mega network to create awareness and better image about the roles of pharmacists in NPHPs.

\section{Study limitations}

The strength of this survey was that there is statistically comparable and valid number of participants from all the groups of the physicians with different levels of experience. Majority of the physicians are welcoming the pharmacists to take active role in NPHPs.

There are over 885,000 registered physicians practicing in the country. One of the limitations is number of physicians participating in this study which is limited to 129. As this study was conducted only in South India, it can be considered as a pilot study to test the method and get some insights in physicians' perceptions on pharmacist role in NPHPs. A larger national level study covering all parts of India would give more insights to the situation. Such a study will be more useful to start negotiations with policy makers to include pharmacists in national health programs, policies and make them part of health care team.

\section{CONCLUSION}

The closer professional relationship between the pharmacists and physicians is always essential in improving the quality of patient care. From this survey it is clear that the younger physicians are more welcoming the pharmacists to take up new role and challenges in NPHPs. Ninety-six percent of responding physicians are very comfortable or somewhat comfortable to collaborate with pharmacists as part of health care team. Maximizing the roles and scope of pharmacists to deliver a variety of patient-centered primary care and public health, in collaboration with physicians is a proven and existing paradigm of care that can be effectively implemented. ${ }^{31}$ Development of liaison between pharmacists and prescribers mainly depends on worthwhile contribution by pharmacists towards better patient care through patient counseling, drug therapy monitoring, adverse drug reaction monitoring and reporting, and unbiased drug information to the doctors. ${ }^{32}$ Most physicians felt that the pharmacists can take important roles like dissemination of information, patient counseling and improving of patient adherence. The student should be trained to collaborate with other health professionals and to enhance the quality of life through improved health for the global community. ${ }^{33}$ The associations and curriculum development committees, pharmacy students and in-service pharmacists could focus patient care areas so that, the future pharmacists are prepared to take up the roles. Further national level large scale studies are required to make strategies and discussions with the policy makers.

\section{ACKNOWLEDGEMENTS}

We wish to thank all volunteers and participating physicians for being the part of this important survey. We would also like to thank Dr. Eluri Eshwar Reddy and Mr. K. S. N. Murthy for their assistance in data collection and during the preparation of this article.

Funding: None

\section{CONFLICT OF INTEREST}

None declared 
Ethical approval: None sought as not required for this kind of study according to the ethics guidelines at the University of Helsinki.

\section{ABBREVIATIONS USED}

NPHPs: National Public Health Programs; WHO: World Health Organization; MDGs: Millennium Development goals.

\section{REFERENCES}

1. Harvard University: Global Equity Initiative. Joint Learning Initiative - Human resources for health and development: A joint learning initiative: 2004. Available from: http://www.who.int/hrh/documents/JLi_hrh_report.pdf. [Last accessed on December 26, 2014].

2. GARG S, SINGH R, GROVER M. India's health workforce: Current status and the way forward. Natl Med J India. 2012;25(2):111-3.

3. International Pharmaceutical Federation. FIP Global Pharmacy Workforce report: 2012. Available from: http://www.fip.org/files/members/library/FIP_ workforce_Report_2012.pdf. [Last updated on June 25, 2015].

4. World Health Organization. World Health Report: 2006. Available from: http:// www.who.int/whr/2006/whr06_en.pdf?ua=1. [Last accessed on June 25, 2015].

5. World Health Organization. Global Health Workforce Alliance: 2014. Available from: http://www.who.int/workforcealliance/countries/57crisiscountries.pdf?ua=1. [Last accessed on January 06, 2015].

6. Berger D. Corruption ruins the doctor-patient relationship in India. BMJ. 2014;348:g3169

7. Medical Council of India. Annual Report 2010-2011. Available from: http://www. mciindia.org/pdf/Annual\%20Report.pdf. [Last accessed on April 02, 2015].

8. Rao M, Rao KD, Kumar AKS, Chatterjee M, Sundararaman T. India: Towards Universal Health Coverage 5 - Human resources for health in India. Lancet. 2011;377(9765):587-98.

9. World Health Organization. Forty-Seventh World Health Assembly - Resolution WHA 47.12, Role of the pharmacist in support of the WHO revised drug strategy. Available from: http://www.europharmforum.org/file/7412. [Last accessed on October 18, 2014]

10. World Health Organization. The report of WHO Consultative Group on "The role of pharmacist in the health care system" New Delhi; 1988.

11. Sheth PD, Reddy MVSP, Vaidya R, Gharat M, Revikumar KG, Mondal S, et al. A Report on Challenges and Opportunities for Pharmacists in Health Care in India. WHO-India Country Office and South East Asian FIP-WHO Forum of Pharmaceutical Associations; 2007. Available from: http://www.searpharm. org/\#!annual-reports/c1yen. [Last accessed on September 12, 2014].

12. Roshan KS, Smriti K, Sushma D. South East Asian FIP - World Health Organization Forum for Pharmaceutical Associations and WHO-India Country Office, Challenges and Opportunities for Pharmacists in Health Care in India. Am J Pharm Educ. 2010;74(2):Article 33

13. South East Asian FIP - World Health Organization Forum for Pharmaceutical Associations and WHO-India Country Office - FIP Challenge on TB Round 1: Compilation of a reference document of Pharmacists' innovative approaches to target early education, delivery of DOTS, rational use, public education in TB care and control in India; 2012. Available from: http://www.searpharm.org/ resources/PDF_files/REPORT\%20final.pdf. [Last accessed on January 23, 2014].

14. Ministry of Health and Family Welfare, Government of India. National Health Policy 2002 (India). Available from: http://www.mohfw.nic.in/showfile. php?lid=2325. [Last accessed on June 23, 2015].

15. Department of Pharmaceuticals, Ministry of Chemical and Fertilizers, Government of India. National Pharmaceutical Policy 2002 (India). Available from: http:// nppaindia.nic.in/may-2002/policy-02.html. [Last accessed on June 23, 2015].

16. Department of Health and Family Welfare, Ministry of Health and Family
Welfare, Government of India, New Delhi, India. Available from: http://mohfw. nic. in/index4.php?lang=1\&level=0\&linkid=316\&lid=1610. [Last accessed on November 01, 2014].

17. Ministry of Health and Family Welfare, Government of India, New Delhi, India. Major programs. Available from: http://www.mohfw.nic.in/index4.php?lang=1\& level $=0 \&$ linkid=316\&lid=1610. [Last accessed on November 12, 2014].

18. Wilbur K, Beniles A, Hammuda A. Physician perceptions of pharmacist roles in a primary care setting in Qatar. Globalization and Health. 2012;8:12. [doi:10.1186/1744-8603-8-12]

19. Hassali MA, Awaisu A, Shafie AA, Saeed MS. Professional training and roles of community pharmacists in Malaysia: Views from general medical practitioners. Malaysian Family Physician. 2009;4(2\&3):71-6.

20. Sarriff A, Nordin N, Hassali MAA. Extending the Roles of Community Phar macists: Views from General Medical Practitioners. Med J Malaysia. 2012;67(6):577-81.

21. Merlin NJ. Pharmacy careers: an overview. Asian J Pharm Sci. 2011;1(1):1-3.

22. Basak SC, Sathyanaraya D. Pharmacy Education in India. Am J Pharm Educ. 2010;74(4):68

23. Maddirala Venkata SPR, Kielgast P, Udhumansha U, Airaksinen M. Public Health and Patient Care Aspects in Indian Pharmacy Curriculum: A Comparison between DPharm, BPharm and PharmD Programs. Curr Pharm Teach Learn. 2015;7(1):84-93

24. National Health Mission. Framework for Implemention of National Health Mission 2012 - 2017. Ministry of Health and Family Welfare, Government of India. Available from: http://nrhm.gujarat.gov.in/Images/pdf/nhm_framework for_implementation.pdf. [Last accessed on January 06, 2015].

25. Department of Health and Family Welfare, Ministry of Health and Family Welfare, Government of India. Annual Report 2013-2014. Available from: http:// nrhm.gov.in/images/pdf/media/publication/Annual_Report-Mohfw.pdf. [Last accessed on January 06, 2015].

26. Framework for Action on Interprofessional Education \& Collaborative Practice (WHO/HRH/HPN/10.3). The Health Professions Network Nursing and Midwifery Office within the Department of Human Resources for Health, World health Organization: 2010. Available from: http://whqlibdoc.who.int/hq/2010/ WHO_HRH_HPN_10.3_eng.pdf?ua=1. [Last accessed on January 06, 2015].

27. Kelly D V, Bishop L, Young S, Hawboldt J, Phillips L, Keough TM. Pharmacist and physician views on collaborative practice: Findings from the community pharmaceutical care project. Can Pharm J (Ott). 2013;146(4):218-26.

28. Maddirala Venkata SPR, Kielgast P, Udhumansha U, Airaksinen M. Pharmacy students' knowledge and attitude on the role of pharmacists in national public health programs in India. FIP Congress 2014, Thailand; 2014. Available from: https://www. fip.org/abstracts? page=abstracts\&action=item\&item $=10628$. [Last accessed on June 25, 2015].

29. Revised National Tuberculosis Control Program. DOTS-plus guidelines, 2010 Central TB Division, Directorate General of Health Services. Ministry of Health and family welfare, Government of India. Available from: http://tbcindia.nic. in/pdfs/DOTS_Plus_Guidelines_ Jan2010.pdf. [Last accessed on January 06, 2015].

30. Rajeswari R, Balasubramanian R, Bose MS, Sekar L, Rahman F. Private Pharmacies in Tuberculosis Control - A neglected link. Int J Tuberc Lung Dis. 2002;6(2):171-3.

31. Giberson S, Yoder S, Lee MP. Improving Patient and Health System Outcomes through Advanced Pharmacy Practice: A Report to the U.S. Surgeon General. Office of the Chief scPharmacist. U.S. Public Health Service. Dec 2011

32. Ramesh A, Nagavi BG. General practitioners' perceptions about the extended roles of the community pharmacists in the state of Karnataka: A study. Indian J Pharm Sci. 2006;68:36-40. DOI: 10.4103/0250-474X.22961.

33. Toklu HZ, Hussain A. The changing face of pharmacy practice and the need for a new model of pharmacy education. J Young Pharmacists. 2013:5:38-40. DOI: dx.doi.org/10.1016/j.jyp.2012.09.001

Article History: Submission Date: 31-05-16; Revision Date: 30-07-16; Accepted Date: 21-08-16.

Cite this article: Venkata SPRM, Kielgast P, Udhumansha U, Airaksinen M. Pharmacists In National Public Health Programs In India: A Pilot Study Highlighting Physicians' Perceptions. J Young Pharm. 2017;9(1):47-54. 